\title{
Potensi Serangan Hama Lalat Buah Bactrocera sp (Diptera: Tephritidae) pada beberapa Komoditas Hortikultura di Pasar Rakyat Kota Kefamenanu
}

\author{
Maria Marselina Bay dan Gonsianus Pakaenoni ${ }^{\mathrm{b}}$ \\ ${ }^{a}$ Fakultas Pertanian, Universitas Timor, Kefamenanu, TTU - NTT, Indonesia, email: marselinabay87@gmail.com \\ ${ }^{b}$ Fakultas Pertanian, Universitas Timor, Kefamenanu, TTU - NTT, Indonesia, email: gonsipakaenoni@gmail.com
}

\section{Article Info}

Article history:

Received 04 November 2020

Received in revised form 27 Desember 2020

Accepted 05 Januari 2021

DOI:

https://doi.org/10.32938/sc.v6i01.1200

\section{Keywords:}

Lalat Buah

Bactrocera passiflorae

Pasar rakyat

Kota Kefamenanu

\section{Abstrak}

Buah dan sayur adalah contoh komoditas yang banyak diperdagangkan di pasar rakyat karena merupakan salah satu kebutuhan pokok masyarakat. Adanya serangan lalat buah pada buah dan sayur yang diperdagangkan di pasar rakyat menjadi salah satu penyebab rendahnya kualitas pada komoditas-komoditas tersebut. Informasi tentang infestasi lalat buah pada komoditas hortikultura yang diperdagangkan di pasar rakyat masih terbatas. Tujuan penelitian ini adalah untuk mendapatkan informasi terkait kemampuan lalat buah untuk menginfestasi komoditas-komoditas yang diperdagangkan di pasar rakyat kota Kefamenanu. Penelitian dilakukan dengan metode survei dan pengambilan beberapa jenis komoditas yang diperdagangkan, tahapan pemeliharaan dan identifikasi dilakukan di laboratorium Pendidikan Biologi Universitas Timor pada bulan Juli 2020 sampai dengan bulan September 2020. Hasil penelitian menunjukkan terdapat lima spesies lalat buah yang menyerang beberapa jenis komoditas hortikultura yang diperdagangkan di pasar rakyat yaitu Bactrocera dorsalis yang menyerang cabai rawit, cabai keriting, cabai besar, belimbing, jambu dan tomat. Bactrocera carambolae menyerang belimbing. Bactrocera albistrigata menyerang cabai keriting, cabai rawit dan jambu biji. Sedangkan Bactrocera passiflorae menyerang jambu biji. Dari hasil penelitian ini didapatkan informasi penting bahwa hama lalat buah tidak hanya menyerang tanaman hortikultura pada areal pertanian, namun dapat pula menyerang komoditas hortikultura yang telah dipanen dan diperdaga ngkan di pasar rakyat kota Kefamenanu.

\section{Pendahuluan}

Komoditas hortikultura merupakan komoditas potensial yang mencakup jenis buah-buahan, jenis sayur-sayuran, jenis obat-obatan dan jenis tanaman hias. Komoditas ini dapat dijadikan andalan masyarakat sebagai sumber pangan dan sumber pendapatan. Potensi dan peluang pasar komoditas hortikultura semakin meningkat seiring dengan meningkatnya permintaan masyarakat terhadap buah dan sayuran yang bermutu tinggi. Dengan demikian nilai ekonomis buah maupun sayuran meningkat sehinggga memicu persaingan dagang antara pasar tradisional dan pasar modern dalam menyediakan komoditas yang berkualitas baik. Kualitas dan kebersihan buah dan sayuran di pasar tradisional jauh lebih rendah dibandingkan pasar modern. Beberapa faktor tersebut antara lain suhu, kelembaban, serangan hama, dan penyakit (Nawawi, 2018). Salah satu penyebab rendahnya kualitas buah dan sayuran lokal yang terdapat di pasar rakyat adalah adanya serangan hama lalat buah. Serangan lalat buah dapat berpengaruh terhadap kualitas dan kuantitas buah (Astriyani, 2014). Bertelurnya lalat buah dalam buah dan larva yang menetas dari telur tersebut akan merusak daging buah, sehingga buah menjadi busuk dan hal ini sangat merugikan. Kerugian kuantitas yang diakibatkan adalah berkurangnya nilai ekonomis buah dan sayuran, sedangkan kerugian kualitasnya yaitu buah menjadi busuk dan terdapat bercak warna hitam yang tidak layak dikonsumsi.

Sejauh ini telah banyak dilaporkan serangan hama lalat buah pada arealareal pertanian tanaman hortikultura, namun sedikit sekali informasi terkait serangan lalat buah pada komoditas hortikultura yang telah dipanen dan diperdagangkan di pasar rakyat maupun pasar-pasar tradisional. Beberapa spesies lalat buah juga dilaporkan menyerang buah-buahan yang diperdagangkan di pasar Tugu Bandar Lampung. Jenis lalat buah yang menyerang buah mangga, belimbing, dan jambu biji adalah $B$. carambolae, sedangkan yang menyerang buah pepaya dan jeruk adalah $B$. papayae untuk buah jeruk, cabai keriting, dan alpukat $B$. dorsalis (Nawawi, 2018).

Pasar rakyat kota Kefamenanu merupakan salah satu sentra perdagangan komoditas hortikultura di kabupaten Timor Tengah Utara. Berdasarkan hasil survei diketahui beberapa jenis komoditas hortikultura dalam jumlah besar mudah busuk sehingga menyebabkan kerugian bagi para pedagang. Penyebab rusaknya komoditas-komoditas tertentu disebabkan oleh berbagi faktor, diantaranya tingkat kelembaban tempat penyimpanan dan juga kemungkinan adanya serangan lalat buah. Berdasarkan hasil pengamatan, area pasar rakyat memiliki kelembaban cukup tinggi dan didukung oleh ketersediaan sumber daya yang cukup, memungkinkan lalat buah untuk berkembang biak dengan baik. Tingginya populasi lalat buah menyebabkan banyaknya kerusakan pada komoditas hortikultura yang diperdagangkan. Lalat betina yang meletakkan telur pada buah-buahan maupun sayuran menyebabkan kerusakan dan berkurangnya nilai jual komoditastersebut.

Berdasarkan hasil pengamatan ini, maka tujuan penelitian ini adalah untuk mengetahui potensi serangan lalat buah pada berbagai jenis komoditas hortikultura yang diperdagangkan di pasar rakyat kota Kefamenanu. Hasil dari penelitian ini sebagai informasi penting bagi masyarakat secara umum dan bagi para pedagang khususnya. Jika lalat buah berpotensi untuk menyerang komoditas tertentu agar dapat dilakukan upaya pengendalian sehingga dapat mengurangi tingkat kerusakan buah dan sayur dan juga dapat mengurangi tingkat kerugian bagi para pedagang.

\section{Metode}

Penelitian dilaksanakan dari bulan Juli-September 2020 yang dilaksanakan di Kelurahan Kefamenanu Selatan, Kecamatan Kota Kefamenanu. Identifikasi lalat buah dilakukan di Laboratorium Pendidikan Biologi
Universitas Timor. Bahan yang digunakan adalah komoditas hortikultura (Cabai rawit, Cabai besar, Cabai keriting, Tomat, Belimbing, Jeruk nipis, Jambu biji, Pare, Terong, Pisang dan Pepaya) yang diperdagangkan di pasar rakyat (Tabel 1), lalat buah, pasir halus yang telah disaring.

Tabel 1. Jenis Komoditas Hortikultura di Pasar Rakyat Kota Kefamenanu yang digunakan sebagai Sampel Mikro habitat Lalat Buah yang akan diidentifikasi

\begin{tabular}{ccc}
\hline \multirow{2}{*}{ No } & \multicolumn{2}{c}{ Jenis Buah } \\
\cline { 2 - 3 } & Nama Lokal & Nama Ilmiah \\
\hline 1 & Cabai rawit & Capsicum frutescens \\
2 & Cabai merah besar & Capsicum annuum $\mathrm{L}$ \\
3 & Cabai keriting & Capsicum annumm L \\
4 & Belimbing & Averrhoa carambola $\mathrm{L}$ \\
5 & Jeruk nipis & Citrus aurantifolia \\
6 & Jambu biji & Psidium guajava \\
7 & Tomat & Solanum lycopersicum \\
8 & Pare & Momordicata charantina $\mathrm{L}$ \\
9 & Terong & Solanum melongena \\
10 & Pisang & Musa sp \\
11 & Pepaya & Carica papaya \\
\hline
\end{tabular}

Penelitian dilaksanakan dengan cara mengumpulkan berbagai jenis komoditas hortikultura dari pasar rakyat di Kota Kefamenanu, kemudian dibiakkan dalam media pasir halus hingga menjadi imago. Imago kemudian diidentifikasi secara langsung yaitu dengan menggunakan kunci identifikasi lalat buah. Populasi dari penelitian ini adalah seluruh komoditas hortikultura yang diperdagangkan di pasar rakyat kota Kefamenanu. Sampel penelitian berupa jenis-jenis komoditas hortikultura yang berperan sebagai inang dari hama lalat buah diantaranya : cabe besar, cabe rawit, cabe keriting, jeruk nipis, belimbing wuluh, pare, terong, jambu biji, pepaya dan pisang.Penelitian dilaksanakan dengan cara mengumpulkan berbagai komoditas hortikultura yang diperdagangkan di pasar rakyat kota Kefamenanu. Sampel komoditas hortikultura lalu dibiakkan dalam media pasir halus hingga menjadi imago kemudian diidentifikasi secara langsung yaitu dengan menggunakan kunci identifikasi The Australian Handbook For The Identification Of Fruit Flies Version 3.1 .

Komoditas-komoditas hortikultura yang telah dikumpulkan dari pasar rakyat dimasukkan ke dalam keranjang plastik kemudian diletakkan di atas nampan plastik yang telah berisi campuran tanah dan pasir halus sebagai media perkembangan larva lalat buah. Sampel tersebut lalu ditutup dengan kain sifon dengan tujuan agar larva lalat buah tidak melompat keluar dari wadah pemeliharaan. Setelah kurang lebih 14 hari, sampel komoditas dibuka untuk memastikan bahwa larva telah berkembang menjadi pupa. Pupa-pupa yang ada pada media pasir lalu dikumpulkan dengan cara menyaring pasir. Pupa yang sudah dikumpulkan ditempatkan dalam gelas plastik yang telah diberi label dan diisi dengan pasir halus dan tidak diberi perlakuan bahan kimia. Ketika lalat buah muncul/menetas dari pupa, imago lalat buah lalu dipindahkan ke dalam botol sampel yang berisi alkohol $70 \%$ agar tubuh lalat buah tidak rusak dan dapat diidentifikasi. Lalat buah kemudian diidentifikasi di laboratorium dengan mengacu pada kunci identifikasi yang digunakan.Data yang dikumpulkan dalam penelitian ini yakni jenis lalat buah yang teridentifikasi dari berbagai komoditas hortikultura yang diperdagangkan di pasar rakyat kota Kefamenanudan jumlah lalat buah yang diperoleh.

Data penelitian dianalisis dengan cara mengidentifikasi secara morfologi berupa venasi sayap, tipe lateral postsutural vittae, warna skutum dan 
pola yang terdapat pada abdomen dari spesies-spesies lalat buah yang ditemukan pada sampel komoditas hortikultura.

\section{Hasil dan Pembahasan}

\section{Jenis Lalat Buah yang Menyerang Komoditas Hortikultura di Pasar} Rakyat

Hasil penelitian menunjukkan bahwa terdapat beberapa jenis komoditas hortikultura di pasar rakyat kota Kefamenanu yang terinfestasi oleh lalat buah. Jenis-jenis komoditas yang terinfestasi lalat buah yaitu cabai rawit, cabai besar, cabai keriting, tomat, belimbing dan jambu biji. Sedangkan pisang, terong, jeruk nipis dan pare tidak ditemukan adanya infestasi lalat buah. Jumlah lalat buah yang diidentifikasi sebanyak 545 individu. Setelah dilakukan identifikasi morfologi berdasarkan tipe venasi sayap, tipe lateral postsutural vittae, warna skutum dan pola yang terdapat pada abdomen, maka spesies lalat buah yang ditemukan pada lokasi pasar rakyat yaitu : Bactrocera dorsalis,, Bactrocera carambolae, Bactrocera albistrigata, Bactrocera passiflorae (Tabel 2).

Tabel 2. Jenis-Jenis Komoditas Hortikultura dari Lokasi Pasar Rakyat Kefamenanu yang diserang oleh Lalat Buah

\begin{tabular}{ccccc}
\hline No & $\begin{array}{c}\text { Komoditas } \\
\text { Terinfestasi }\end{array}$ & $\begin{array}{c}\text { Jenis Lalat Buah } \\
\text { Yang Diperoleh }\end{array}$ & Famili & Genus \\
\hline 1 & Cabai rawit & Bactrocera dorsalis & Tephritidae & Bactrocera \\
2 & Cabai besar & Bactrocera dorsalis & Tephritidae & Bactrocera \\
3 & Cabai keriting & Bactrocera dorsalis & Tephritidae & Bactrocera \\
4 & Tomat & Bactrocera dorsalis & Tephritidae & Bactrocera \\
& Belimbing & Bactrocera carambolae & Tephritidae & Bactrocera dorsalis \\
& & Tephritidae & Bactrocera \\
& & Bactrocera albistrigata & Tephritidae & Bactrocera \\
6 & Jambu biji & Bactrocera dorsalis & Tephritidae & Bactrocera \\
& & Bactrocera passiflorae & Tephritidae & Bactrocera \\
\hline
\end{tabular}

Spesies lalat buah yang diperoleh dari lokasi pengambilan sampel dan paling banyak menyerang komoditas-komoditas hortikultura yang diperdagangkan adalah pada spesies $B$. dorsalis yang diperoleh dari cabai rawit, cabai keriting, cabai besar, tomat, belimbing dan jambu biji. Hal ini berkaitan dengan spesies $B$. dorsalis merupakan jenis lalat buah yang memiliki tanaman inang sangat banyak, dan merupakan hama polifagus sehingga dikatakan hama yang paling merusak pada tanaman hortikultura (Susanti, 2016). Menurut Siwi (2006) B. dorsalis memiliki tanaman inang yang bervariasi, biasanya menyerang tanaman buah-buahan dan memiliki daerah persebaran yang luas serta merupakan hama polifagus. Menurut Drew (2011) bahwa beberapa tanaman inang pada $B$. dorsalis adalah : mangga dan cabai namun selain itu spesies ini juga dapat menginfeksi jeruk, pepaya, jambu biji, jambu air, alpukat, kopi arabika, pisang. Berdasarkan hasil survei dan pengamatan selama proses pengambilan sampel dari pasar rakyat, beberapa sampel yaitu cabai rawit, cabai keriting, cabai besar dan jambu biji cukup banyak jumlahnya di pasaran sehingga cukup mendukung lalat betina $B$. dorsalis untuk meletakkan telur. Bertelurnya lalat betina menyebabkan kerusakan pada komoditas-komoditas tersebut.

Spesies lainnya yang diperoleh dari hasil rearing komoditas hortikultura dari pasar rakyat adalah spesies $B$. albistrigata yang didapat dari jambu biji. Menurut Siwi \& Hidayat (2006) tanaman inang bagi B. albistrigata adalah jambu biji, jambu air, jambu bol, nangka dan berpotensi sebagai hama tanaman Syzygium spp atau kelompok tanaman Myrtaceae. Tanaman liar tropikal almond atau badam (Terminalia catappa) merupakan inang utama di Malaysia. Hal ini sesuai dengan pendapat Kusuma (2012) yang menyatakan jenis lalat buah yang ditemukan menyerang jambu air dalhari (Syzygium samarangense) di Kabupaten Sleman salah satunya adalah B. albistrigata. Spesies ini juga menyerang pada jambu bol, jambu biji, dan nangka.

Spesies lain yang di peroleh ialah $B$. carambolae dari sampel belimbing. Menurut Siwi (2006), belimbing adalah inang utama dari spesies ini, meskipun sering juga ditemukan pada tanaman buah lainnya. Hal ini didukung dengan pendapat dari Tariyani et al., (2013) bahwa B. carambolae menyerang buah belimbing, jambu biji, jambu air, kluwih, tomat dan cabai. Sama halnya dengan $B$. dorsalis, spesies B. carambolae juga bersifat polifag yaitu menyerang lebih dari satu jenis inang. Spesies terakhir yang ditemukan pada sampel komoditas dari pasar rakyat adalah $B$. passiflorae yang ditemukan pada sampel jambu biji. Sejauh ini laporan mengenai serangan spesies ini pada berbagai jenis tanaman pertanian maupun hortikultura di Indonesia sangat jarang, sehingga dengan adanya penemuan spesies ini perlu dilakukan penelitian lanjutan pada kecamatan-kecamatan yang ada di kabupaten Timor Tengah Utara untuk mengetahui tingkat persebaran dari spesies ini. Keseluruhan spesies lalat buah yang diperoleh dapat dilihat pada tabel 3 .

\section{Jumlah Spesies Lalat Buah yang Diperoleh Dari Sampel Komoditas Hortikultura}

Lalat buah yang dikoleksi dari sampel komoditas hortikultura dilakukan penghitungan jumlah masing-masing spesies. Sampel-sampel yang diambil dari pasar rakyat kota Kefamenanu secara keseluruhan sudah dapat mewakilkan keseluruhan komoditas hortikultura yang menjadi inang daripada lalat buah dan diperdagangkan pada pasar tersebut meskipun dari hasil pengamatan hanya sebagian dari sampel yang teridentifikasi diserang oleh lalat buah. Tingkat serangan setiap spesies dapat dilihat dari banyaknya spesies tersebut ditemukan pada sampel komoditas hortikultura yang dikumpulkam dari pasar rakyat (Tabel 4)

Tabel 3. Spesies Lalat Buah Hasil Identifikasi dari Komoditas Hortikultura yang diperdagangkan di Pasar Rakyat Kota Kefamenanu

\begin{tabular}{|c|c|c|}
\hline Spesies & Foto Sampel Lalat Buah & $\begin{array}{c}\text { Acuan } \\
\text { (The Australian Handbook } \\
\text { For The Identification Of } \\
\text { Fruit Flies Version 3.1) }\end{array}$ \\
\hline
\end{tabular}
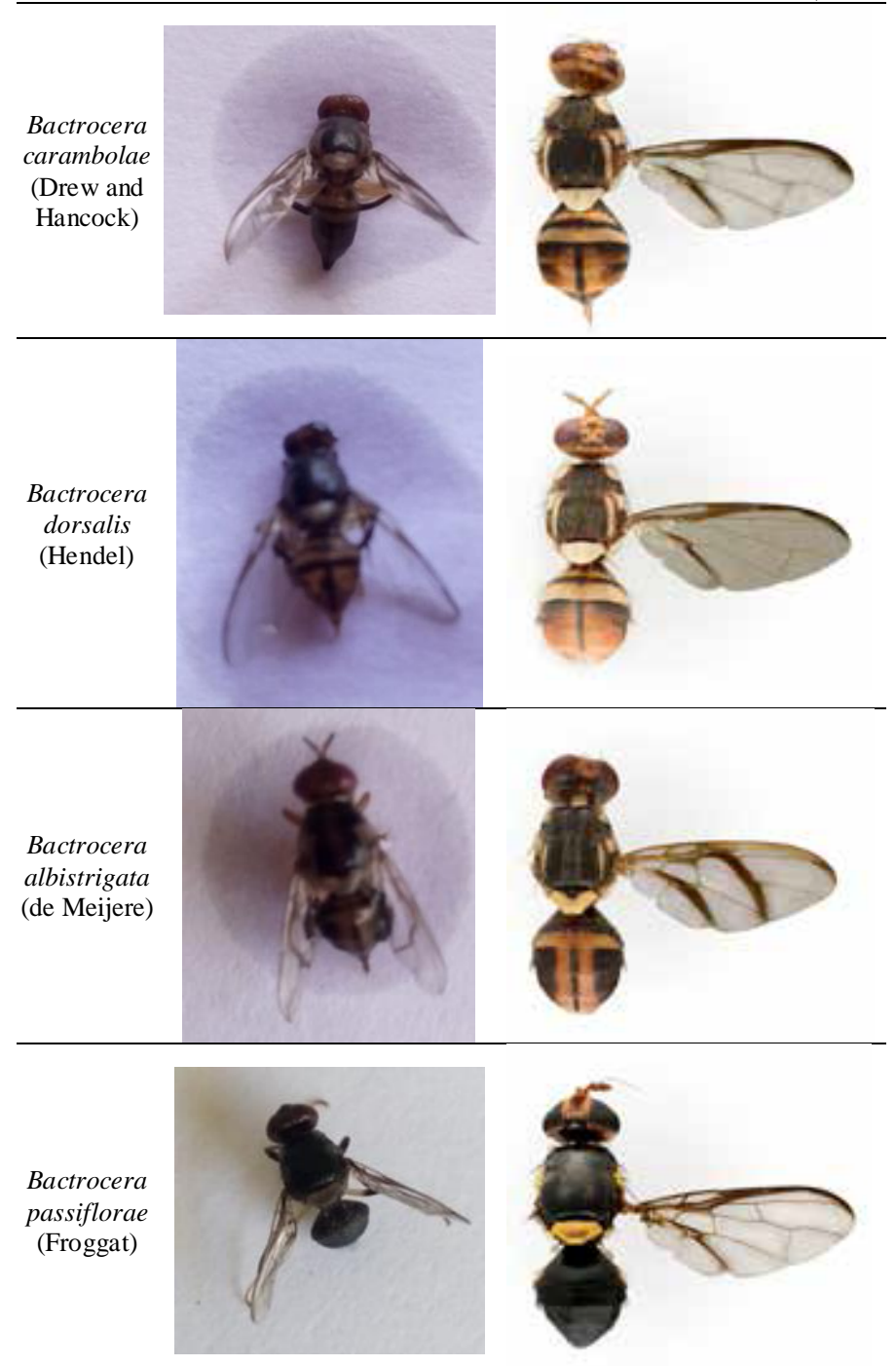

Tabel 4. Jumlah Spesies Lalat Buah yang Menyerang Komoditas Hortikultura di Pasar Rakyat Kefamenanu

\begin{tabular}{cccc}
\hline \multirow{2}{*}{ No } & Komoditas & Jenis Lalat Buah & \multirow{2}{*}{ Jumlah } \\
& Terinfestasi & Yang Diperoleh & \\
\hline 1 & Cabai rawit & Bactrocera dorsalis & 287 \\
2 & Cabai besar & Bactrocera dorsalis & 60 \\
3 & Cabai keriting & Bactrocera dorsalis & 40 \\
4 & Tomat & Bactrocera dorsalis & 4 \\
5 & Belimbing & Bactrocera carambolae & 7 \\
& & Bactrocera dorsalis & 3 \\
6 & Jambu biji & Bactrocera albistrigata & 93 \\
& & Bactrocera dorsalis & 102 \\
& & Bactrocera pasiflorae & 14 \\
\hline
\end{tabular}

Spesies lalat buah yang diperoleh dari lokasi pengambilan sampel dengan jumlah individu paling banyak adalah spesies $B$. dorsalis yang diperoleh dari cabai rawit, cabai keriting, cabai besar, tomat, belimbing dan jambu biji dengan jumlah individu sebanyak 496 individu. Tingginya lalat buah spesies $B$. dorsalis diduga terkait dengan adanya ketersediaan inang pada pasar. Diketahui inang dari lalat buah ini bervariasi dan di daerah Jawa terutama dikenal menyerang tanaman cabai (Siwi \& Hidayat, 2006). Ketersediaan inang utama yaitu cabai yang cukup melimpah pada saat penelitian dilaksanakan menyebabkan peningkatan populasi spesies $B$. dorsalis. B. carambolae yang diperoleh dari sampel belimbing berjumlah 7 individu. Hal ini dapat dipengaruhi oleh ketersediaan belimbing di pasaran yang berdasarkan hasil pengamatan sangat jarang ditemukan di pasaran. Spesies lalat buah lainnya yang diperoleh adalah B. albistrigata dari sampel jambu biji berjumlah 93 individu, sedangkan $B$. passiflorae yang djuga diperoleh dari sampel jambu biji berjumlah 14 individu. Sahetapy et al. ,2019) menyatakan bahwa tingkat 
serangan lalat buah juga sangat tergantung dari keberadaan populasi lalat buah di lapangan. Populasi tinggi tingkat serangannya juga cenderung tinggi. Disamping itu juga dipengaruhi oleh beberapa faktor lain diantaranya suhu, kelembapan, cahaya, angin, tanaman inang dan musuh alami. Hal ini sebagaimana dijelaskan oleh Siwi (2005), faktor yang memengaruhi hidup lalat buah adalah suhu, kelembaban, cahaya, angin, tanaman inang dan musuh alami. Tingkat serangan lalat dipengaruhi juga oleh tekstur buah tanaman inang. Hasil penelitin (Syahfari, 2013) menyatakan bahwa lalat buah hanya menyerang buah dengan tekstur kulit buah yang lunak, warna daging buah, dan bau buah.Adanya hubungan antara tingkat kematangan buah dengan dinamika/fluktuasi populasi lalat buah di lapangan juga dilaporkan oleh (Manurung $d k k$., 2013). Jika dilihat bahwa komoditas hortikultura berupa buah dan sayur yang diperdagangkan adalah buah dan sayur yang telah matang dan siap untuk dikonsumsi, sehingga ketersediaannya di pasar dapat menarik lalat buah betina untuk datang dan meletakkan telur.

\section{Simpulan}

Hasil penelitian menunjukkan dari 11 jenis komoditas hortikultura yang diperdagangkan di pasar rakyat dan merupakan inang dari lalat buah, enam diantaranya berpotensi diserang oleh lalat buah, yang ditandai dengan diperolehnya beberapa spesies lalat buah setelah melalui tahapan rearing sampel-sampel komoditas tersebut. Sampel-sampel yang digunakan dalam penelitian cukup mewakilkan komoditas-komoditas hortikultura diperdagangkan di pasar rakyat kota Kefamenanu. Terdapat lima spesies lalat buah yang menyerang beberapa jenis komoditas tersebut yaitu Bactrocera dorsalis yang menyerang cabai rawit, cabai keriting, cabai besar, belimbing, jambu dan tomat. Bactrocera carambolae menyerang belimbing, Bactrocera albistrigata menyerang jambu biji dan Bactrocera passiflorae menyerang jambu biji. Berdasarkan hasil penelitian ini, maka dapat disimpulkan bahwa komoditas-komoditas hortikultura yang menjadi inang daripada lalat buah dan diperdagangkan di pasar rakyat kota Kefamenanu dapat diserang oleh lalat buah.

\section{Pustaka}

Astriyani, N. (2014): Keragaman dan Dinamika Populasi Lalat Buah (Diptera: Tephritidae) yang Menyerang Tanaman Buah-buahan di Bali. Tesis. Denpasar: Program Pascasarjana Universitas Udayana

Drew, D. (2011): The Australian Handbook For The Identification of Fruit Flies. Version 1.0. Plant Health Australia. Canberra, ACT

Kusuma, A. A. (2012). Identifikasi Jenis Lalat Buah (Diptera: Tephritidae) pada Jambu Air Dalhari (Syzygium samaragense) di Kabupaten Sleman, Daerah Istimewa Yogyakarta. Yogyakarta: Universitas Negeri Yogyakarta.

Manurung, B., Prastowo, P. \& Tarigan, E.E. 2013. Pola Aktivitas Harian Dan Dinamika Populasi Lalat Buah Bactrocera Dorsalis Complex Pada Pertanaman Jeruk Di Dataran Tinggi Kabupaten Karo Provinsi Sumatera Utara. Jurnal Hama dan Penyakit Tumbuhan Tropika, 12(2): 103-110.

Nawawi, R. 2018. Kelimpahan Lalat Buah (Diptera: Tephritidae) Pada Berbagai Jenis Buah-Buahan Yang Terdapat Di Pasar Tugu Bandar Lampung (Sebagai Sumber Belajar Biologi Materi Keanekaragam Hayati Pada Peserta Didik Sma Kelas X Semester Ganjil). PhD Thesis. UIN Raden Intan Lampung.

Sahetapy B, Uluputty M.R, Naibu L. 2019. Identifikasi Lalat Buah (Bactrocera spp.) Asal Tanaman Cabai (Capsicum annuum L.) dan Belimbing (Averrhoa carambola L.) Di Kecamatan Salahutu Kabupaten Maluku Tengah. Jurnal Agrikultura 2019, 30 (2): 63-74

Siwi, S.S. (2005): Eko-Biologi Hama Lalat Buah. Bogor: BB-Biogen

Siwi, S.S. \& Hidayat, P. 2006. Taksonomi dan bioekologi lalat buat penting di Indonesia (Diptera: Tephritidae). Kerjasama Balai Besar Penelitian dan Pengembangan Bioteknologi dan Sumberdaya Genetik Pertanian dengan Departement of Agriculture, Fisheries and Forestry Australia.

Susanti, Z. 2016. Kehadiran lalat buah Bactrocera spp (Diptera : Tephritidae) Dan Parasitoidnya (Hymenoptera : Braconidae) Pada Kebun Kopi Di Takengon Aceh Tengah. Tesis Program Magister, Institut Teknologi Bandung

Syahfari, H. 2013. Identifikasi Hama Lalat Buah (Diptera: Tephritidae) pada Berbagai Macam Buah-buahan. Ziraa'ah Majalah Ilmiah Pertanian, 36(1): 32-39.

Tariyani, J., Patty, A. \& Siahaya, V. G. (2013). Identifikasi Lalat Buah (Bactrocera spp) di Chili, Bitter Melon, Jambu, dan Jambu Bol di Kota Ambon. Agrologia, 2(1), 73-85. 